\title{
La construcción de identidades corporales alternativas en los límites de un proyecto educativo hegemónico ${ }^{1}$
}

Alejandra Ruiz Mariel $^{*}$

\begin{abstract}
Resumen: La investigación aspiró a conocer la contribución de la educación física en la construcción de las identidades corporales infantiles en el contexto europeo actual. Desde el enfoque socio-constructivista (GERGEN, 1992; GIDDENS, 1997; CASTELLS, 1998; HERNÁNDEZ, 2000; BRAIDOTTI, 2000; BUTLER, 2003, entre otros), la metodología construccionista (GUBA; LINCOLN, 1994) y el estudio etnográfico (DENZIN, 1997) se reflejan las construcciones de identidades corporales alternativas, en los límites de un proyecto educativo hegemónico, que cuestionan las formas tradicionales del saber y anuncian la emergencia de un sujeto corporal político que merece una nueva articulación pedagógica.
\end{abstract}

Palabras clave: Educación física escolar; Identidad corporal; Práctica pedagógica.

\section{Aproximación AL ESTUDIO}

Uno de los interrogantes del estudio, realizado en la ciudad de Barcelona en un centro educativo de primaria caracterizado por un alto porcentaje de población inmigrante, fue "¿Qué corporeidades se construyen en el desencuentro de las representaciones de la infancia y el cuerpo sustentadas por los discursos educativos de la

\footnotetext{
'Este artículo se desprende de la investigación realizada para adquirir el titulo de Doctora en Educación por la Universidad de Barcelona en enero de 2011. La investigación titulad: Experiencias de corporeidad en la escuela primaria actual. Una narrativa corporal desde la perspectiva de los sujetos, fue realizada en la ciudad de Barcelona durante el período 2002/2005 bajo la dirección del Dr. Hernández Fernando de la Universidad de Barcelona, Facultad de Bellas Artes y la Dra. Alonso Cristina de la Universidad Barcelona, Facultad de Educación.

Universidad Nacional de Lujan, delegación San Fernando. Buenos Aires, Argentina. E-mail: rumar98@yahoo.com
} 
educación física escolar y la infancia en el contexto actual?" Este interrogante asoma avanzado el estudio, frente a la distancia entre las concepciones, representaciones y percepciones de infancia y de cuerpo de los discursos de la administración educativa, de la educación física, de los docentes del centro y de los niños y niñas. Los desencuentros se muestran en varias imágenes que comparto a continuación como testimonio de un estudio cuyo interrogante ha sido ¿Cuál es el papel de la educación física escolar en la construcción de las corporeidades infantiles en el contexto actual? Pude explorar, describir e interpretar esta pregunta desde una investigación hermenéutica y fenomenológica que permitió un mejor acercamiento al fenómeno objeto de estudio, con posibilidades de producción y transferencia de conocimientos importantes para el desenvolvimiento educativo general.

El objetivo de mi investigación fue comprender de qué manera la educación física escolar contribuye a la construcción de corporeidades infantiles en el contexto actual de la ciudad de Barcelona. Analicé que dicen de la infancia y del cuerpo los discursos de la administración educativa, así como aquello que hacen (y dicen que hacen) los docentes del centro estudiado, sin perder de vista lo que dicen y hacen los niños y niñas.

El análisis de las evidencias reunidas muestra lo que he llamado un 'desencuentro', es decir, una distancia entre las representaciones de los sujetos-cuerpos infantiles sostenidas por los discursos de la administración educativa (entre los cuales se cuentan los docentes) y las representaciones y comprensiones de la infancia real, es decir, la 'infancia de la experiencia'. Entender este desencuentro incide en la comprensión de los procesos de adquisición de identidades corporales infantiles atravesados por un contexto multicultural y multimediático diverso. Mostrando además, las complejidades de una realidad social novedosa para el centro escolar en cuestión, y sobre el cual se perfilan especulaciones didácticas en base a complejas y dificultosas relaciones pedagógicas aun sin explicación. 


\section{UN ANÁLISIS POSIBLE DE LOS DISCURSOS EDUCATIVOS, DOCENTES E INFANTILES.}

En principio los discursos de la administración educativa enfatizan el componente socializador de la escuela y se identifica a la educación como un "proceso normalizador e integrador" que tiene como objetivo insertar a los sujetos en la sociedad y lograr que éstos aporten 'lo mejor de sí mismos'. Situando a la Educación Física como colaboradora para dicho fin, recuperándola como "[...] un medio de difundir la idea de jerarquía, de orden, de disciplina, de persistencia y de esfuerzo individual" (SOARES, 1994, p. 20) y revalorizando en su dimensión "científica" la capacidad para perfeccionar física, mental y moralmente a los ciudadanos, volviendo al hombre más apto para su función de suministrar fuerza de trabajo y a la mujer para la maternidad, su noble tarea hacia un proyecto de sociedad en construcción (SILVA, 1999)

En este sentido los discursos de la administración educativa sostienen que: "El niño se transforma en alumno y más tarde en ciudadano útil" en Ley Orgánica General del Sistema Educativo (LOGSE, 1990, p.2). Desde esta premisa de futuro, la extensión de la educación debería contribuir a la mejora del bienestar social y a la reducción de la desigualdad. En esta posición, el sujeto infantil aparece como posibilidad de futuro, es decir, como proyección. Por otro lado, el énfasis en la producción de 'ciudadanos del futuro' implica la negación de la infancia como etapa valiosa en sí misma; la proyección en la infancia de hoy de los hombres y mujeres del mañana implica concebirla como una fase de preparación, lo cual le quita su presente y traspone su papel y capacidad de acción para el futuro. (MARRERO; CAMPAÑÁ; RUIZ; ALONSO; HERNÁNDEZ, 2005)

Similar es la posición de Inés, la docente que imparte clases de educación física en infantil y desarrolla tareas de Caps d' Estudis $^{2}$ en la primaria. Inés opina: "[...] en primaria tienes unas posibilidades

${ }^{2}$ Es la responsable de la organización didáctico- pedagógica del centro investigado.

Movimento, Porto Alegre, v. 17, n. 04, p. 83-100, out/dez de 2011. 
increíbles de poder tú ir trabajando a tu manera y obtener lo que deseas poco a poco". Este fragmento de entrevista puede leerse desde el sostenimiento de una representación del sujeto infantil como sujeto de la 'espera', es decir, sujeto que espera ser transformando en otro durante un proceso educativo en donde el deseo adultodocente marca el destino posible, el de una corporeidad culturalmente aceptada, que le dará garantías de constituirse en sujeto de la 'acción' (ciudadano-ciudadana) logradas las configuraciones socialmente aceptadas y hegemónicamente determinadas.

Desde esta visión, parecería ignorarse que los niños y las niñas son ante todo cuerpos que llevan impresos una perspectiva cultural de sí mismo así como de sus particularidades (IHDE, 2004), y que es allí mismo en cuya carne, en donde se inscribe, construye y reconstruye el significado (MCLAREN, 1994, 1997; GIROUX; MCLAREN; 1998) es decir, el lugar en donde se construyen los significados que dan cuenta de la mutua e íntima relación entre éste y la subjetividad es decir, la intersubjetividad, constitutiva de la subjetividad, en donde las formas materiales se subjetivizan y lo subjetivo se materializa. Proceso que supone la relación mutuamente constitutiva de la estructura social y el deseo, es decir, una relación dialéctica entre la organización material de la interioridad y modos culturales de materialidad que subjetivamente integramos, lo que representa un verdadero proceso de 'encarnamiento' (MCLAREN, 1997).

Desde este entendimiento la visión de Inés parecería estar más próxima de la representación de un sujeto signado por destinos prefijados y en concordancia con concepciones identitarias corporales únicas, alejadas de todo cuestionamiento crítico de lo social y del reconocimiento del sujeto corporal con capacidad de agencia y en proceso constante de cambio. Tal planteo no es novedoso: se trata de una forma de reformular desde otro lugar el eterno problema del disciplinamiento, la culturización y la reproducción, que en definitiva se empecinan en negar en todas sus formas posibles la presencia activa de un sujeto deseante, con su propia naturaleza humana, sus propias condiciones materiales de vida y existencia, y sus propios 
saberes experienciales situados. Negar el origen, la cultura, el contexto, el género o el sexo $^{3}$, la cultura, es negar al sujeto y tender a la fabricación o culturización pensada desde los discursos dominantes de la educación ${ }^{4}$. No obstante no se trata de negar la existencia de lo evidente en cuanto de formas visibles de ser en la escuela, de lo que se trata es de considerarlas como formas que merecen una especial atención para ser cambiadas, o transformadas. Lo que supone un posicionamiento dominante de la cultura educativa en general y en particular de la educación física en la escuela.

Por otro lado, la representación de 'sujeto incompleto's, no preparado, funciona como argumento para la instrucción, esto puede verse reflejada en las siguientes expresiones de la administración educativa y de un docente del centro educativo investigado:

[...] se prepararán para incorporarse a la vida activa o para acceder a una educación posterior $[y]$ recibirán la formación que les capacite para asumir sus deberes y ejercer sus derechos como ciudadanos. [LOGSE 6 , 1990, p. 6,9; LOCE, 2002].

Nosotros tenemos plena conciencia que no tenemos alumnos fáciles, esta es una población distinta, es como lo llamamos nosotros un colectivo multicultural, por eso hemos elaborado un plan

\footnotetext{
${ }^{3}$ Esta idea explorada por Braidotti (2004) evidencia cómo en esa naturalización de la identidad la idea de diferencia adquiere un matiz negativo.

${ }^{4}$ Nuevamente los discursos de la administración inciden en las representaciones del sujeto infantil. La manera en que la legislación aborda la cuestión de la diversidad nos brinda un ejemplo muy claro al respecto. Hasta la aparición de un reciente documento del MINISTERIO DE EDUCACION (MEC) (2004), la diversidad remitía exclusivamente a una anormalidad que requería una actuación de normalización/adecuación. La LEY ORGÁNICA DE CALIDAD DE LA EDUCACIÓN (LOCE) O LEY ORGÁNICA 10/2002 promulgada el 23 de diciembre de 2002 y sus concreciones la asocian a discapacidades y/o problemas de adaptación al sistema escolar, mientras que la LOGSE la sitúa en relación con las diferencias culturales y de género (LOGSE, p. 11). Cf. MARRERO, CAMPAÑÁ, RUIZ, ALONSO Y HERNÁNDEZ (2005).

${ }^{5}$ Una primera imagen de la representación de los sujetos infantiles en los documentos legales analizados es precisamente la necesidad de que el niño y la niña dejen de ser tales lo antes posible para transformarse primero en alumnos y posteriormente en adultos útiles y productivos para la sociedad.

${ }^{6}$ La Ley de Ordenación General del Sistema Educativo de España de 3 de octubre de 1990 (publicada en el BOE de 4 de octubre) fue una ley educativa española, promulgada por el gobierno socialista y sustituyó a la Ley General de Educación de 1970. Ha sido derogada por la Ley Orgánica de Educación (LOE), en el año 2006.
} 
estratégico de atención a la diversidad multicultural que ya venimos desarrollando desde hace un par de años. Que intenta encausar los desvíos. Así como la atención que le podemos dar a partir del aula de acogida [...]. (Conversación informal en la dirección del centro con el director, Javier, junio de 2005)

La preocupación compartida por los docentes y directivos de la escuela, expresada en reuniones de claustro cuya intención es reforzar la asunción de un proyecto de escuela construido por todos, muestra la fractura o desencuentro ante lo real, ante lo diferente y diverso. Y la emergencia de hacer encajar lo novedoso, distinto y diferente con lo que ya existe.

Esa diversidad (tanto cultural como individual) desde los discursos, frecuente e insistentemente, está vinculada con situaciones de anormalidad que requieren actos de normalización y adecuación. La $\mathrm{LOCE}^{7}$, como ejemplo más crudo, presenta la diversidad ligada a tres únicos casos: alumnos extranjeros, alumnos superdotados intelectualmente y alumnos con necesidades educativas especiales. Este concepto de diversidad deja afuera los casos que no se integren a esas categorías pensadas desde la administración, aunque se trate de casos que no merezcan ser considerados como anormales sino como resultantes de situaciones contextuales diversas y diversificadas, incluso dentro del mismo territorio.

La concepción del sujeto infantil de la escuela primaria reducido psicológicamente, se refuerza en la legislación educativa a partir de la psicología del desarrollo, que insiste en la idea de un sujeto que se desarrolla cognitivamente en una serie de pasos y etapas de carácter universal en el marco de un ideal de racionalidad científica adulta. Esto marca una tendencia a pensar más en términos de enseñanza que de aprendizaje, ya que en esta visión la tarea de la escuela consiste en propiciar los medios y las situaciones donde se permita ese desarrollo, que se irá alcanzando a través de los procesos

\footnotetext{
${ }^{7}$ La Ley Orgánica de Calidad de la Educación o Ley Orgánica 10/2002 fue una ley española promulgada el 23 de diciembre de 2002 por el segundo gobierno del José María Aznar (PP), siendo ministra Pilar del Castillo, y que pretendía reformar y mejorar la educación en España. No llegó a aplicarse.
} 
evolutivos correspondientes. Lo que justifica además el énfasis de todos los documentos que colocan a la escuela primaria como preparación para etapas posteriores, como fase inicial en la adquisición de habilidades intelectuales y sociales básicas para un largo proceso de formación de ciudadanos, eludiendo las experiencias individuales que hacen a la constitución de cada uno de los sujetos.

Por su parte, los discursos de la educación física que encuentran su modo de expresión en la crítica sobre los modelos sociales y la intención de potenciar valores y actitudes democráticas encuentran un punto de inflexión cuando conceptualizan o representan a un sujeto del aprendizaje ideal; es decir, no reconocido como sujeto de diferencias o saberes particulares con potencialidad:

El alumno debe construir los conocimientos a partir de actividades individuales y en grupo que le permitan descubrir las posibilidades de practicar actividades físicas en su entorno propio, prevenir situaciones de riesgo asociadas a la práctica de actividades físicas y desarrollar una mirada crítica frente a ciertas imágenes corporales difundidas por los medios de comunicación. (GENERALITAT..., 2007, p. 21860)

El sólo hecho de nombrar a los sujetos del aprendizaje como alumnos, refuerza la idea de lo universal, unida a la idea de 'sujeto competente' que se deriva de los principios capitalistas-mercantilistas transferidos de la gestión empresarial a la lógica escolar, que enfocan el desarrollo personal a partir del trabajo y del cuidado del propio cuerpo, desde la asimilación de actitudes y valores centrados en la autogestión del cuerpo y la conducta motriz.

Sara, docente de educación física de todos los cursos de primaria del centro investigado, sostiene al 'cuerpo' como la condición necesaria para el desarrollo de capacidades y competencias individuales y sociales, al servicio de los discursos hegemónicos. Desde su perspectiva el cuerpo resulta el instrumento que asegura la inserción de los sujetos al entramado social dominante, atribuyéndole a la educación física un papel instrumental (BARBERO GONZÁLEZ, 2001) en el entrenamiento de las habilidades 
deportivas específicas que garantizan tal inserción, desvinculando de este modo los procesos históricos, sociales, culturales, afectivos y sociales que forman parte de todo desarrollo motriz. Una vez más, se refuerza la concepción de una educación física escolar que, si bien recurre a procesos de reflexión y de crítica social, halla su sentido educativo amparado en un sujeto del aprendizaje considerado como máquina, es decir, como ente que aprende por repetición y logra alcanzar ciertos estereotipos técnicos y/o biológicos que son legitimados.

La enseñanza y el aprendizaje de la educación física en la etapa de la educación primaria ha de fundamentarse en la adquisición de aquellos conocimientos, habilidades y competencias relacionadas con el cuerpo y su actividad motriz que contribuyan al desarrollo integral de la persona y a la mejora de la calidad de vida. (GENERALITAT..., 2007, p. 21860)

M:-Sara, te pregunté lo de la planificación para ubicarme a esta altura del año. Veo que ahora están haciendo deporte, que tienen la salida de tenis...

S:-El fútbol, vóley, básquet, ayer hicieron vóley, pues hoy fútbol; ayer al igual que hoy unos hicieron tenis y la mitad vóley y hoy también la mitad hicieron tenis y la otra mitad fútbol

S:-Bueno, luego tenemos gimnasia y salidas: la de tenis, la de Torre Baró, la del canal Olímpico, la de tenis. Prácticamente lo que trabajo en las clases son los deportes, la gimnasia, la entrada en calor, y juegos" [Entrevista con Sara, viernes 28 de abril de 2005]

Por último, en los contenidos propuestos por la escuela puede leerse una amplia gama de saberes socialmente válidos que se espera sean distribuidos a todos los sujetos en la educación primaria. Se organizan en cinco apartados que se repiten en los diferentes ciclos ${ }^{8}$ complejizándose desde una secuenciación sustentada en las etapas

\footnotetext{
'Los apartados son: (1) El cuerpo, la imagen y percepción; (2) Habilidades motrices y cualidades físicas básicas; (3) Actividades físicas y salud; (4) Expresión corporal; y (5) El juego.
} 
del desarrollo motor, cuestión que permite nuevamente concebir al sujeto infantil como sujeto universal, que atravesando en forma lineal diferentes etapas desarrolla su corporeidad y motricidad, desvinculando el proceso de los aspectos sociales y culturales que influyen en ese desarrollo.

La visión de desarrollo autónomo resulta para Sara el argumento válido para planificar sus clases desde una posición que refleja una concepción de la educación física escolar basada en paradigmas mecanicistas, biologicistas y tecnicistas los que, actualmente son cuestionados desde la didáctica y la pedagogía de la educación física ${ }^{9}$, y desde perspectivas más humanistas y socio-constructivistas.

Además, en las clases de Sara se observa que no están incluidos todos los contenidos del discurso oficial, al prevalecer el deporte y la gimnasia como ha sido posible observar en el trabajo de campo, se privilegiando un aspecto de la cultura física corporal, sobre otros, sometiendo a los niños y niñas que no se sientan interesados a encontrar una buena excusa para huir de la educación física.

Entre los discursos de la administración educativa y los de Sara, el encuentro se basa en un modelo de educación física que sustenta la concepción de un sujeto del aprendizaje como vacío, incompleto, a histórico etc. que sólo será reconocido como sujeto de la acción a partir de lograr el dominio de ciertos estereotipos motrices y corporales y en términos de competencia impuestos desde la cultura dominante.

\footnotetext{
${ }^{9}$ Actualmente, tanto en Europa como en Latinoamérica la cuestión del 'deporte' y su enseñanza en el contexto escolar es un tema presente en las agendas de investigadores. La problemática surge a partir de cuestionamientos críticos de la sociedad, del deporte, de la educación y la pedagogía, que revisan tanto las finalidades y funciones sociales de la escuela desde diferentes corrientes marxistas -por ejemplo BROHM (1978), SERGIO (1986, 1987); BRACHT (1988-19891996-2001) - como las finalidades de la educación física inmersa en ese universo. Son varias las críticas compartidas, algunas de ellas son que: -"El deporte reproduce valores y principios de la sociedad burguesa, contribuyendo al mantenimiento de las mismas relaciones sociales. La práctica del deporte escolar, en función de la educación estética que fomenta, contribuye a la docilidad de los cuerpos y, por lo tanto, al comportamiento de sumisión a los patrones vigentes. - El deporte de alto rendimiento -modelo del deporte escolar [...] - fomenta la selección y la discriminación privilegiando a los más aptos en detrimento de los menos habilidosos- Por su peso político y económico, conquistó la hegemonía en el ambiente escolar produciendo la monocultura deportiva y no permitiendo o dificultando el acceso de los estudiantes a las otras manifestaciones de la cultura corporal de movimiento" (BRACHT; CAPARROZ, 2008, p. 59).
} 
Lo que inevitablemente deja a fuera a la mayoría de los niños y niñas sujetos de la investigación, quienes llegan a la ciudad de Barcelona a partir de contextos en su mayoría rurales de países centroamericanos y sin haber completado su escolarización, marcando la presencia activa de otras subjetividades corporales, de otros saberes y proyectos corporales y motrices útiles, los cuales se trazan a partir de experiencias infantiles, cargadas de historias y vivencias personales, modos, lógicas y comprensiones diferenciadas, que escapan a las miradas de una escuela cuyo proyecto moderno impide considerar otras producciones corporales, sociales y culturales componedoras de una nueva ciudadanía, como se muestra en las siguientes imágenes:

[...] es una pena, pero muchos de estos niños terminarán en la cárcel o siendo criminales organizados en bandas para robar. Porque desgraciadamente son niños de la calle, donde la familia no existe, porque trabaja o porque no les interesa nada de ellos. Son niños que a los 4 años no conocen un parque, sólo conocen la calle o la tv y a los 7 ya van solos a todos sitios. [Docente en una charla informal en la hora de patio el 11 de mayo de 2005]

A modo de ejemplo, la imagen, intenta mostrar cómo la escuela se inscribe en las corporeidades infantiles así como en sus deseos, los que discurren y moviliza entre la organización institucional, el currículo y el deseo educativo de los tutores. En este sentido, el sujeto infantil se mueve dentro de los márgenes de una lógica escolar, disciplinar y pedagógica pensada con algunos fines particulares, pero lo hace sin pérdida, sino aprovechando los espacios y los tiempos creados para organizar otras prácticas y modos particulares de habitar.

\section{LA CONSTRUCCIÓN DE CORPOREIDADES ALTERNATIVAS}

Ahí donde el mundo de los adultos y el infantil se distancian suceden verdaderos procesos de constitución subjetiva produciéndose 
verdaderas prácticas alternativas de construcción de corporeidades: procesos en que los sujetos infantiles integran las diversidades moldeando nuevas identidades corporales sociales, las cuales a su vez producen saberes útiles particulares a partir de conjugar otras formas de conversación y de transmisión de poder y de resistencia. En este sentido, el poder de la escuela y de la educación física dentro de ella permite revitalizarlas como espacios vitales de socialización y construcción corporal.

En estas situaciones se conjugan saberes históricos construidos en experiencias de vida particulares, cada una de las cuales "no se limita a la esfera de lo escrito, al mundo de los letrados y los científicos, sino que [se constituye] integrando las diferencias, las 'maneras de decir y hacer". (GÓMEZ SOLLANO, 2010, p.3); (el agregado es mío).

Los usos y las funciones de los saberes históricos producidos en la experiencia temporal de los sujetos constituyen modos de producción y de transferencia de las identidades corporales, entendidas como identidades sociales, políticas, geográficas, étnicas, generacionales y de género en las que se han experienciado y aprendido las eternas relaciones entre saber y poder.

Los saberes personales, que por lo general poco tienen que ver con los saberes que la escuela y la disciplina contemplan o valorizan, resultan "[...] descalificados, no legitimados, contra instancias teóricas unitarias que pretenden filtrarlos, jerarquizarlos y ordenarlos en nombre de un conocimiento verdadero, en nombre de los derechos de una ciencia que algunos poseerían" (FOUCAULT 2, 2002 citado por GÓMEZ SOLLANO, 2010, p. 22).

2 FOUCAULT, M. La arqueología del saber. Buenos Aires: Siglo XXI, 2002.

Cuando los saberes personales y escolares no encuentran sentido sino en mundos 'paralelos', las corporeidades resultantes son fragmentadas, desvinculadas, en permanente especulación con la realidad, y opuestas a la formación integral del sujeto infantil que los 
discursos educativos desean. Mostrando como las prácticas alternativas que llevan a construir, cambiarlo o sustituirlo algo, devienen en respuestas innovadoras ${ }^{10}$ con sentido para el sujeto. Mostrando que los sujetos infantiles son productores de alternativas corporales que los proyectan a futuro, permitiéndoles trascender el aquí y el ahora, poniendo en juego los saberes disponibles e históricamente construidos. Para ello, recuperan marcas identitarias originales que les permiten cambiar y tomar decisiones articuladoras de las diferencias, el poder y las resistencias.

Lo institucionalizado, los marcos normativos, los discursos legitimados de la educación física y los educativos y escolares en general, suponen la referencia para la reelaboración de saberes; los que a su vez vuelven a la institución e impactan en ella, marcando la ruptura con las condiciones dadas (institucionales, discursos e imaginarios de infancia y cuerpos). Las situaciones de crisis, generan condiciones para el cambio, descubriendo la singularidad de cada sujeto en la diversidad de respuestas posibles.

Sara me explica que están preparando los bailes para el acto de Sant Jordi que será en el teatro y que harán dos bailes: una danza tradicional catalana y un baile moderno. En la clase les dice que se prepare uno de los grupos que hará la danza. Se ponen en el centro 5 parejas mixtas el resto de los niños y niñas están sentados a un costado y observan a los que bailarán (...). Pone la música: es una marcha y los niños y niñas bailan. Mientras ejecutan los movimientos rígidos de la misma, dos niños realizan movimientos de cadera fuera de la coreografía. Sara va pasando por las parejas y corrigiendo los movimientos ondulantes que no forman parte de ese baile. [Observación en la clase de educación física de Sara del 15 de abril de 2005]

\footnotetext{
${ }^{10} \mathrm{La}$ innovación se enraíza en la autodeterminación del sujeto para introducir novedades a lo presente, a partir de las opciones con que cuenta, las cuales remiten a un punto anterior de posiciones que discute interiormente a partir de lo externo.
} 
Los chicos saben que ese baile es diferente del que ellos están realizando, pero el desafío consiste en agregar lo propio a lo ajeno. A su manera, muestran esa 'cultura parcial corporal', ese tejido contaminante que conecta culturas y a la vez impide que la cultura incluya lo que está fuera de sus límites, como sostiene BHABBA (1996, p.96): "[...] se trata de algo como el 'entre-medio' [in-between] de la cultura, desconcertadamente parecido y diferente".

La irrupción de proyectos corporales contra-hegemónicos ${ }^{11}$, trazados por fuera de los discursos educativos de los cuerpos disciplinados y ordenados, abre e instaura un nuevo orden y una nueva posibilidad para pensar. En los siguientes relatos puede leerse cómo las diferencias indican que hay otras formas deseables de ser en la escuela:

Jénia no sabe bien por qué le gusta esta escuela, pero sabe que lo mejor es el patio, porque es la hora de jugar con sus amigos, y de jugar al fútbol, lo que más le gusta. La hora de educación física también le encanta porque es para jugar. Antes, cuando la escuela era distinta, había un profesor, Jesús, que los separaba: es decir, las niñas iban al gimnasio a jugar con los aros, las pelotas o lo que quisieran, y los varones se quedaban en la cancha jugando al fútbol. Y a ella esto no le gustaba, porque le gustaba jugar al fútbol, pero nunca podía [...]. [Charla informal en hora de patio, 5 de noviembre de 2005]

Luís baila, se mueve inquietamente, mientras escribe, María le pregunta si es así como se trabaja en la clase a lo cual Luís le responde que a él no le impide dibujar. María insiste en pedirle a Luís que piense cómo se trabaja en clase, que considere quedarse quieto para dibujarse y que intente hacerlo como los otros para que no distraiga y moleste a sus compañeros, Luís la mira, y le dice que lo intentará. Se detiene, dibuja y le dice a María que lo mire, que lo está intentand. [Observación en aula de acogida, 27 de septiembre de 2005]

\footnotetext{
${ }^{11}$ Los análisis de estas corporeidades alternativas se presentan principalmente en los capítulos $\mathrm{IX}$ y $\mathrm{X}$ de mi tesis, aunque pueden leerse también en otras escenas. Las cual puede ser consultada en http://www.tdx.cat/handle/10803/21614
} 
Como pequeñas pinceladas de discursos infantiles, expresan corporeidades que están poniendo en cuestión los límites de un proyecto educativo hegemónico, así como formas tradicionales del saber, dando a conocer herramientas para pensar proyectos $\mathrm{y} / \mathrm{o}$ imágenes de futuro (GÓMEZ SOLLANO, 2010, p.12) y anunciando los márgenes, huecos y bordes de un discurso pedagógico que, obturado de saberes hegemónicos, es desbordado por otros saberes y marcas que están anunciando la emergencia de un sujeto corporal político para el cual es necesario encontrar una nueva articulación pedagógica. 
The construction of alternative corporal identities in the limits of an hegemonic educational project

Abstract: The present paper describes research that attempted to discover physical education's role in the construction of children's corporal identities in the current European context. Our approach combines a socio-constructivist point of view (GERGEN, 1992; GIDDENS, 1997; CASTELLS, 1998; HERNÁNDEZ, 2000; BRAIDOTTI, 2000, BUTLER, 2003, among others), constructionist methodology (GUBA; LINCOLN, 1994) and ethnographic studies (DENZIN 1997). Our results reveal the construction, beyond the limits of hegemonic educational projects, of alternative corporal identities that put question marks on traditional forms of knowledge and announce the emergence of a political, corporal subject that deserves a new pedagogical articulation.

Keywords: School physical education; Corporal identity; Pedagogical practice.

A construção de identidades corporais
alternativas nos limites de um projeto educativo
hegemônico
Resumo: A pesquisa teve a intenção de conhecer a
contribuição da educação física na construção de
identidades corporais da infância no contexto europeu
atual. Desde o enfoque socioconstrutivista, (GERGEN,
1992; GIDDENS, 1997; CASTELLS, 1998; HERNÁNDEZ,
2000; BRAIDOTTI, 2000; BUTLER, 2003, dentre
outros). A metodologia construtivista (GUBA; LINCOLN,
1994) e o estudo etnográfico (DENZIN, 1997) se reflete
na construção de identidades corporais alternativas,
nos limites de um projeto educativo hegemônico, que
questionam as formas tradicionais do saber e anunciam
a urgencia de um sujeito corporal político que merece
uma nova articulação pedagógica.
Palavras chave: Educação física escolar; Identidade
corporal; Prática pedagógica




\section{REFERÊNCIAS}

BARBERO GONZÁLEZ, J. I. ¿Tenemos algo que decir desde la educación física? Monográfico. Cultura corporal. Ágora para la EF y el Deporte, Valladolid, n. 1, p. 18-36, sept. 2001. Disponible en: <http://www5.uva.es/agora/revista/1/ agora1ignaciobarbero.pdf $>$. Acceso en: 23 jun. 2009.

BHABBA, H. K. El entre-medio de la cultura. In: HALL, S.; DU GAY, P. (Eds.) Cuestiones de identidad cultural. Buenos Aires: Amorrortu, 1996. p. 94-106.

BRACHT, V. Saber y fazer pedagógicos: Acerca da legitimidade da educaçao física como componente curricular. In: CAPARROZ, F. (org.) Educaçao Física escolar. Vitória. Proteoria, 2001.

BRACHT, V. A educación física escolar como campo de vivencia social. Revista Brasileira de Ciencias do Esporte, Sao Paulo, v. 9, n.3, p. 23-39, maio 1988.

BRACHT, V. Educación física y aprendizaje social. Córdoba: Vélez Sarsfield, 1996.

BRACHT, V. Educación física: a busca da autonomía pedagógica. Revista Brasileira de Ciencias do Esporte, Maringá, v.1, n. 0, p. 28-33, 1989.

BRACHT, V.; CAPARROZ, F. Pesquisa em açao: Educacao física na escola. Ujuí: Unijuí. 2008.

BRAIDOTTI, R. Sujetos nómades. Buenos Aires: Paidós, 2000.

BRAIDOTTI, R. Feminismo, diferencia sexual y subjetividad nómade. Barcelona: Gedisa. 2004.

BROHM, J. M. Sociología política del deporte. In: GILI, G. Partisans: Deporte, cultura y represión, Barcelona: Gustavo Gili, [1972] [1978]. p. 17-31.

BUTLER, J. Cuerpos que importan. Buenos Aires: Paidós, 2003.

CASTELLS, M. La era de la información: economía, sociedad y cultura. Madrid: Alianza, 1998.

DENZIN, N. K.. Ethnographic poetics and narratives of the self. In: Interpretative Ethnography, Londres: Sage, 1997. p. 207-208.

GENERALITAT DE CATALUNYA. Departamento de Educación. Decreto 142/2007, de 26 de junio, por el que se establece la ordenación de las enseñanzas de la educación primaria. Diario Oficial de de la Generalidad de Cataluña, n. 4915, p. 21822-21870. Disponible en: <http://www.gencat.cat/diari_c/4915/ 07176074.htm>. Acceso en: 12 jul. 2007.

GERGEN, K. J. El yo saturado. Barcelona: Paidós, 1992. 
GIDDENS, A. Modernidad e identidad del yo: el yo y la sociedad en la época contemporánea. Buenos Aires: Amorrortu, 1997.

GIROUX, H. A.; MCLAREN, P. Sociedad, cultura y educación. Buenos Aires: Miño y Dávila. 1998.

GIROUX, H. La pedagogía radical como política cultural: más allá del discurso de la crítica y el anti-utopismo. In: Pedagogía crítica y cultura depredadora: políticas de oposición en la era posmoderna. Barcelona: Paidós, 1997. p. 47-79.

GÓMEZ SOLLANO, M. Saberes, sujetos y experiencias pedagógicas alternativas. Conceptos y articulaciones. In: ENCUENTRO INTERNACIONAL. GIROS TEÓRICOS, FRONTERAS Y PERSPECTIVAS DEL CONOCIMIENTO TRANSDISCIPLINARIO, 3. 2010. Buenos Aires: Instituto de Investigaciones Gino Gemani. UBA. Facultad de Ciencias Sociales.2010. Disponible en: <http:// girosteoricosbuenosaires.blogspot.com/>. Acceso en: 22 dic. 2010.

GUBA, E. G.; LINCOLN, Y. S., Naturalistic inquiry. Beverly Hills: Sage, 1994.

HERNÁNDEZ, F. Recuperar el poder docente. Una entrevista con Ivor Goodson. Cuadernos de Pedagogía, Barcelona, n. 295, p. 44-50, 2000.

IHDE, D. Los cuerpos en la tecnología: Nuevas tecnologías: nuevas ideas acerca de nuestro cuerpo. Barcelona: Universitat Oberta de Catalunya, 2004.

LOCE. Ley Orgánica de Calidad de la Educación n. 10/2002. Boletín Oficial del Estado, Madrid, n. 307 de 24 dic. 2002. Disponible en: <http://www.cepes.ro/ services/pdf/Spain_qualidad.pdf>. Acceso en: 2 mayo 2004.

LOE. Ley Orgánica de Educación. Boletín Oficial del Estado, Madrid, n. 106, p. 17158-17270, 04 may 2006. Disponible en: http://www.madrid.org/dat_capital/loe/ pdf/loe_boe.pdf. Acceso en: 12 mayo 2004.

LOGSE. Ley de Ordenación General del Sistema Educativo de España de 3 de octubre de 1990. Boletín Oficial del Estado, Madrid, n. 238 de 04 out. 1990. Disponible en http://www.boe.es/aeboe/consultas/bases_datos/doc.php?id=BOEA-1990-24172. Acceso en: 14 mayo 2004.

MARRERO, I.; CAMPAÑÁ, L.; RUIZ, M., ALONSO, C.; HERNÁNDEZ, F. La ausencia de sujeto en la legislación. Cuadernos de pedagogía, Barcelona, n. 350, p. 7982, 2005.

MCLAREN, P. Pedagogía crítica, resistencia cultural y la producción del deseo. Buenos Aires: Ideas. 1994.

MEC. Ministerio de Educación y Ciencia de España. Una educación de calidad para todos y entre todos. Madrid, 2005. 151 p. (Debate educativo). Disponible en: <http://debateeducativo.mec.es/documentos/informe_debate.pdf >. Acceso en: 20 mayo 2004. 


\section{ArtigosOrignais}

RUIZ, Mariel Alejandra. Experiencias de corporeidad en la escuela primaria. Una narrativa corporal desde la perspectiva de los sujetos. 2011. 396 p. Tesis final de doctorado. Universidad de Barcelona. Departamento de Didáctica y Organización educativa. 2011. Disponible en: <http://www.tdx.cat/handle/10803/ 21614>. Acceso en 10 de agosto de 2011.

SERGIO, M. Motricidade humana: uma ciencia do homem! Lisboa: Ministerio da Educaçao e Cultura. 1986. v. 1.

SERGIO, M. Para una epistemología de la motricidad humana. Lisboa: Compendium. 1987.

SILVA, M. da. La educación física en Rio Grande do Sul durante la Republica vieja: apuntes sobre el momento histórico y sobre la formación de profesores. Revista Digital Educación Física y Deportes, Buenos Aires, v. 4, n. 13, mar. 1999. Disponible en: <http://www.efdeportes.com/efd13/rvelhae1.htm>. Acceso en: 20 out. 2008.

SOARES, C. Educação Física: Raízes Européias e Brasil. Campinas, SP; Autores Associados, 1994.

Endereço para correspondência:

Alejandra Ruiz Mariel

Calle Lascano 6514

CP (1408)

Ciudad autónoma de Buenos Aires.

Argentina

Recebido em: 3.09.2011

Aprovado em: 30.10 .2011 
